\title{
World-wide non-mandatory involvement of electricity utilities in the promotion of energy efficiency and the Portuguese experience
}

\author{
José L. Sousa ${ }^{\mathrm{a}, \mathrm{c}, *}$, António G. Martins ${ }^{\mathrm{b}, \mathrm{c}}$, Humberto M. Jorge ${ }^{\mathrm{b}, \mathrm{c}}$ \\ a Polytechnic Institute of Setúbal, Technology School of Setúbal, Portugal, Campus do IPS, Estefanilha, 2910-761 Setúbal, Portugal \\ ${ }^{\mathrm{b}}$ University of Coimbra, Passos das Escolas, 3004-531 Coimbra, Portugal \\ ${ }^{\mathrm{C}}$ Institute for Systems Engineering and Computers at Coimbra (INESC Coimbra), Coimbra, Portugal
}

\section{A R T I C L E I N F O}

\section{Article history}

Received 5 December 2012

Received in revised form

31 January 2013

Accepted 3 February 2013

Available online 15 March 2013

Keywords:

Energy efficiency

DSM

Portugal

\begin{abstract}
A B S T R A C T
The interest in the promotion of energy efficiency by utilities at the demand-side started in the seventies caused by the high prices of oil and suffered a drastic set back during the restructuring of the electricity sector. However, growing awareness on the positive effects of energy efficiency on the economy and on the environment, led many countries/jurisdictions to impose utilities' engagement in the promotion of energy efficiency. In other countries/jurisdictions utilities encourage their customers to improve energy efficiency, on a non-mandatory basis. In this paper, the non-mandatory involvement of electric utilities in the promotion of energy efficiency at the demand-side is addressed. Some worldwide examples are given, detailing the Portuguese experience. Although this participation is important, it seems that countries/jurisdictions with regulatory impositions obtain more satisfying results.
\end{abstract}

(c) 2013 Elsevier Ltd. All rights reserved.

\section{Contents}

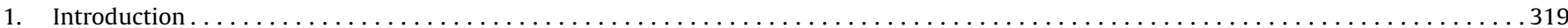

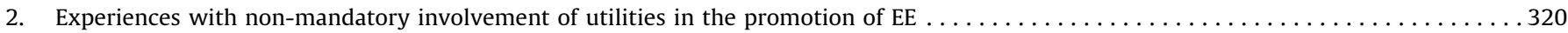

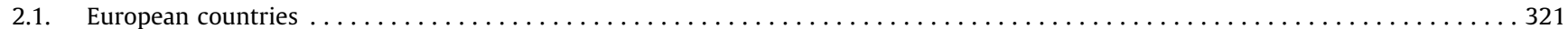

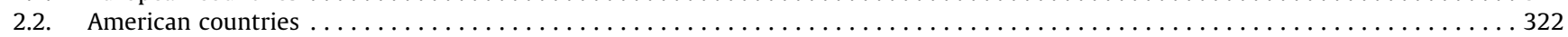

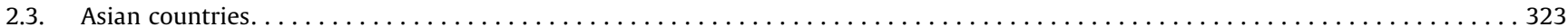

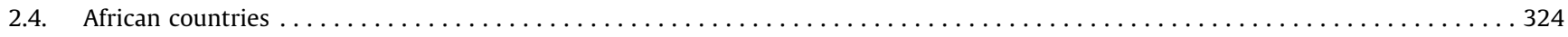

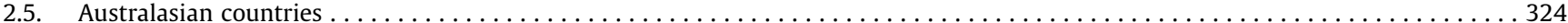

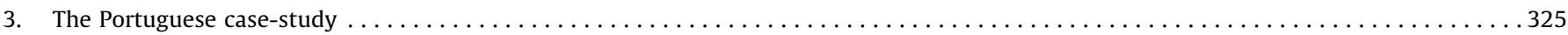

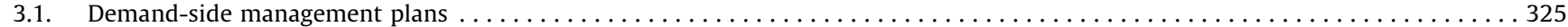

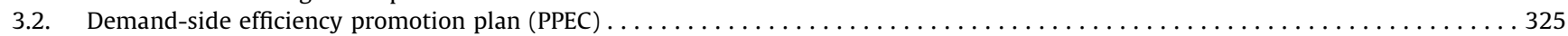

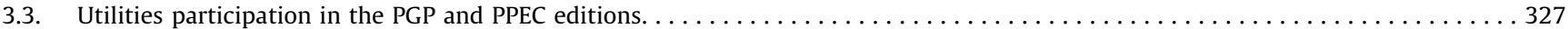

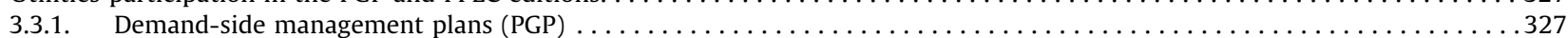

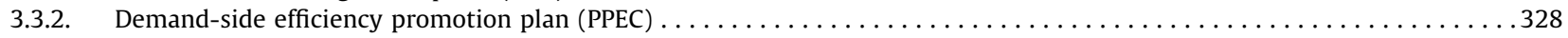

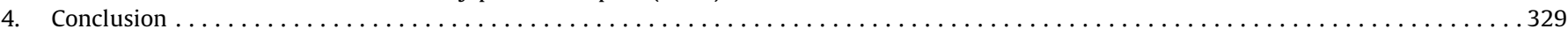

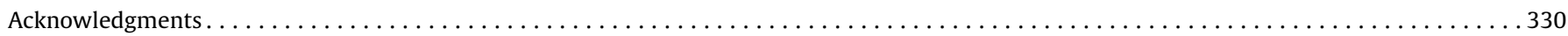

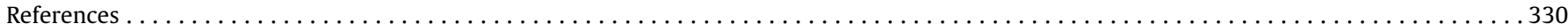

\section{Introduction}

Traditionally, the supply side of the energy system was responsible for ensuring the provision of energy in conditions

\footnotetext{
* Corresponding author at: Polytechnic Institute of Setúbal, Technology School of Setúbal, Portugal Campus do IPS, Estefanilha, 2910-761 Setúbal, Portugal. Tel.: +351265 790000; fax: +351265790043.

E-mail address: jose.luis.sousa@estsetubal.ips.pt (J.L. Sousa).
}

requested by the demand. Ensuring sufficiency and security of supply under the current conditions, where the economy is based on fossil fuels, is no longer viable. Non-fossil resources for energy generation have limitations. Besides the increase of several environmental and health issues/concerns on nuclear energy, uranium is also not an infinite resource. Renewable energy sources are not yet, and probably will not be, based on currently known technologies, a true alternative to fossil fuels, under current and projected consumption levels, due to the low density 
of primary energy flows. Also, the environmental impact of energy use, mainly from fossil sources, is not addressed by the current energy business model [1]. In developing countries, mainly those with very low electrification rates, the need to ensure an electricity supply adequate to a reasonable quality of live is of even greater importance. The infrastructures of the electricity system of those countries are usually old, fragmented and unreliable, with high technical and commercial losses, dependent on expensive and carbon intensive fuels. Power sectors in these countries are subject to increasingly frequent power shortage events. Although these events seldom have a single and the same cause, they are usually associated to underinvestment in infrastructures, increasing demand growth, and natural causes such as drought, hot/cold weather [2]. In these cases, the electricity system does not meet its purpose of ensuring the needs of the population. This inability to deliver the amount of energy required within acceptable quality parameters may be an opportunity for utilities to engage in the promotion of end-use energy efficiency, not only as an opportunity to reduce demand, but also due to social and political pressure. For electric utilities, implementing energy efficiency programmes represents, in the short-term, incurring upfront costs and, in the long-term, losing revenues from electricity sales due to lower consumption values.

Utility-based demand-side management (DSM) programmes started after the oil crises of the 1970s, under regulated environment, when utilities were mostly vertically integrated and quite a number of them publicly-owned. In the early 1990s, DSM programmes were already adopted by many utilities, integrated in resource plans where both the supply and demand side were considered as equivalent alternatives in the planning procedure (addressed as integrated resource planning-IRP). The deregulation of the electricity industry that started in the 1990s, threatened DSM. During this period utilities were more focused in the restructuring process and, due to uncertainties on the availability of funds and to the new regulatory environment, investments in DSM dropped sharply. The availability of funds to energy efficiency programmes managed by utilities is a key factor to involve utilities in developing EE programmes. Altogether, the risks of not recovering the programme costs, the revenues losses, or failing profits, may be discouraging. Several approaches are used to address the loss of revenues or fowling profits that utilities may experience due to successful EE programmes. The most commonly found are decoupling sales from profits and utilities/ shareholder incentives. Decoupling is a process used to compensate utilities for the reduction of sales due to energy efficiency programmes. The rates are periodically adjusted to reflect the difference between actual energy sales and the sales forecast used in the rate setting process. Also, and as a stimulus for the companies to keep working for more savings, some countries/ states created shareholder incentives that reward utilities for the successful implementation of energy efficiency programmes [3].

The participation of utilities in the promotion of energy efficiency (EE) measures is mostly carried out under mandatory regulations. Either through the imposition of savings targets or through mandatory implementation of EE measures, utilities become involved in the promotion of EE. Besides the costs of the programmes, improving EE would, most certainly, reduce the utilities revenues. Some precautions are taken to avoid the companies' financial ruin. Different countries (or jurisdictions) address the issue diversely, for instance, through a mix of programme cost recovery, remuneration of sales, and sharing of benefits from energy efficiency programmes [4]. The most common regulatory mechanisms, according to Sam Swanson [5], are energy efficiency obligations (EEO), integrated resource planning (IRP), stable funding, market adaptation to foster EE investments, requirement of disclosure of demand-side resource opportunities in system resource plans, performance incentives, tariff design, and independent energy efficiency providers.

However, there are some examples of voluntary involvement [6]. In this context, non-mandatory means that companies are not obliged to engage in EE promotion in order to keep their license. Additionally, some temporary programmes involving utilities are also mentioned in this paper. In the next section the involvement of the utilities in the promotion of EE in different countries/jurisdictions in the different continents is addressed, highlighting the cases of non-mandatory involvement. The Portuguese case in presented in Section 3, namely referring the existing regulation for the involvement of electric utilities in the promotion of EE measures under the demand-side plans framework (Section 3.1) and under the demand-side efficiency plans (Section 3.2). The characterization of the involvement of electric utilities in the promotion of EE in Portugal under both programmes is addressed in Section 3.3.

\section{Experiences with non-mandatory involvement of utilities in the promotion of $\mathrm{EE}$}

The ACEEE's State Energy Efficiency Scorecard report, based on an annual evaluation of the US states commitment to foster energy efficiency, with the intent to reveal the best practices, results in benchmarking the efforts of states on EE policies and programmes. In its fifth edition, the 2011 report examines the state policies in six areas, (1) utility and public benefits programmes and policies; (2) transportation policies; (3) building energy codes; (4) combined heat and power; (5) state government initiatives; and (6) appliance efficiency standards. For the assessment of each state's performance regarding utility-sector EE programmes, five items are scored: electricity and natural gas programmes budgets for 2010, incremental electricity programme savings for 2009, energy savings targets (EERS), and performance incentives and alternative regulatory business models. EERS and alternative business models are instruments for the provision of incentives and removal of barriers for the promotion of EE in the demand-side by electric utilities. The results from 2010 and 2011 showed that the states with non-mandatory involvement are among the ones that received the lowest scores in most items, occupying generally the last positions in the ranking, reflecting a weak involvement and results of utilities in the promotion of EE measures. The top positions are generally occupied by states that invest in EE programmes, which set energy savings targets, and that have mechanisms to encourage utilities and to remove disincentives. These are the cases of Vermont, Massachusetts, Rhode Island, Minnesota, and California. These are also the states that accomplished more savings. Generally utilities in these states pursue "deep savings", instead of, the so-called, "lowest-hanging fruit" (typically the replacement of lighting technologies). "Deep savings" approaches focuses on programmes such as whole-building retrofits and comprehensive changes addressing technologies and their use, trying to obtain the most possible savings from each participant customer. The top states accomplished savings above $0.84 \%$ of retail sales while the states without mandatory involvement attained under $0.2 \%$ savings of retail sales $[7,8]$.

Several international organizations, such as the World Bank, the International Finance Corporation (IFC, is a unit of the World Bank), the United Nations Development Program (UNDP), the United States Agency for International Development (USAID), the Asian Development Bank, among others, have been financing DSM activities, through loans, some of them with grants from the Global Environment Facility (GEF). This kind of collaboration for the development of DSM projects helps building local 
expertise, helps the development of more permanent support mechanisms, and facilitates stakeholder involvement. Projects in this context arise mostly as strategies to mitigate the number and frequency of load supply interruptions, due to poor electricity services, high commercial and technical losses, growing demand rates, high costs of supply, and/or low prices to customers. In some countries, according to the Asian Development Bank and the World Bank, DSM projects using CFLs can be between 60 and 90\% cheaper than building new power plants [9]. With that support utilities can find an incentive to implement DSM programmes by influencing customers to reduce demand. Although most of the utilities involved in these programmes are publicly-owned, these donor funding projects provide a good example of the benefits of DSM in developing countries, although some of them were unable make DSM become a part of the country's strategy.

A large number of DSM programmes is based in bulk procurement and distribution of CFLs. These programmes based on the replacement of incandescent bulbs by CFLs can be quickly implemented, and have immediate results to fill capacity and energy gaps. An additional benefit, particularly important for the low-income consumers, is the reduction of the electricity bills. The cost of using CFL can be 1/20th of the cost of adding emergency diesel generators, thus being much less expensive than the alternative. Another advantage of the replacement of incandescent bulbs for CFLs is the reduction in greenhouse gas emissions, meaning that these programmes are suitable for carbon financing, through the Clean Development Mechanism. Also, in many developing countries the use of lighting is usually associated with electric systems peaks, which corresponds to another advantage of the use of CFL and a reason for the popularity of these programmes [2]. The Clean Development Mechanism was created under the Kyoto protocol to support projects that contribute to the reduction of emissions, earning credits on emission reductions that can be sold to industrialized countries [10].

A government clear message is needed in order to involve actors in effective DSM programmes. Hence, political will is fundamental to reduce uncertainty, clearing the government line of action [11,12]. Governmental decisions can benefit stakeholder engagement in the energy efficiency policy. The involvement of governments, private companies, inter-governmental organizations, and NGOs, among others, can help building a political consensus and ensures better conditions for the implementation and success of the programmes, and it can also lead to a better policy design. In some cases these co-operation is mandatory [13]. Nevertheless, even with private interests, utilities can be an interested party of DSM and market transformation projects [14].

\subsection{European countries}

Before the liberalization of the electricity sector, in Austria, as well as in Australia, Belgium, Denmark, France, Germany, Italy and Spain, utilities were involved in DSM and IRP activities. The major programmes were aimed at increasing consumer awareness of rational consumption of energy, through informative campaigns and advice, and improving the use of the production capacity providing time-of-use (TOU) and interruptible tariffs and load management services. These activities could be carried out in co-operation with regional or with municipal utilities. The investments in these programmes were significantly reduced after the liberalization of the electricity sector, due to the pressure of the competitive environment. Environmental concerns were the reason to keep investing in DSM. The rise in energy prices and transmission constraints increased the interest in DSM and energy efficiency [15]. This increased interest was governmental and not industrial. Municipalities and public authorities have taken responsibility for increasing awareness. There are strong incentives for the investment in renewable energy, but the same does not apply to investments in energy efficiency, regardless of the energy efficiency potential. For instance, since the Electricity Act in 2000, distribution system operators are obliged to buy a percentage of electricity generated by renewables, under regulated prices. These costs are charged to the customers as a surcharge on the network tariff [16]. In a competitive environment, investments in energy efficiency and awareness rising are becoming tools to retain customers. The branding has become an important issue [17]. Some regional electric utilities subsidise the purchase of energy efficient equipment for the residential customers, enterprises or public institutions. Some utilities subsidise the installation of gas fired condensing boilers [18]. Utilities also run informative campaigns to encourage more energy efficient behaviours. Although utilities become themselves involved in energy efficiency programmes, in many of those cases they are not obliged. There are no mandatory targets for the contribution of utilities to the reduction of consumption [19].

Energy efficiency in the Wallonia region of Belgium is promoted by giving premiums to energy suppliers for the implementation of energy saving measures [20].

In Cyprus, CFL for the households sector are promoted and subsidized by the government. For each household, five lamps are distributed free of charge by the utility company [21].

Under the 2007 National Energy Efficiency Action Plan (NEEAP) utilities are required to offer information as energy services to end-users, in the Czech Republic [22].

In Ireland, Powersave is a voluntary scheme offered by electricity suppliers to their customers. Consumers will receive financial incentives if they reduce electricity demand on request. The purpose is to use this scheme in generation shortfall, avoiding the load shedding of customers. Also two other schemes are in place to influence customers to change their consumption pattern. The Winter Peak Demand Reduction Scheme provides financial incentives to business consumers that reduce their electric energy consumption during peak hours in winter months (November-February). The Winter Demand Reduction Incentives provides incentives for customers to displace their consumption to off-peak hours [23,24]. The Ireland's Electricity Supply Board (ESB) produced a brochure "Power Savings for Industry" aiming to help industrial customers, consultants, plant designers, and purchasers of equipment, to reduce energy costs by adopting costeffective energy efficient technologies and operating practices. This measure was in place between 1990 and 1995 [25].

In Germany, major industries and utilities agreed to reduce $\mathrm{CO}_{2}$ emissions intensity by $20 \%$ between 1990 and 2005. In return, the German government offered low-interest loans for investments in energy efficiency improvements [26]. Since 2002 supply energy companies, in collaboration with the Germany energy agency (Dena), and supported by the Federal Ministry of Economics and Technology (BMWi), conducted a nationwide energy efficiency campaign ("Initiative EnergieEffizienz") that targeted the households sector, the services and industry (since 2005). The focus of the campaign is to inform customers about EE opportunities in each sector [27]. There is no obligation for utilities to offer EE programmes, even though municipallyowned utilities have been offering EE programmes, under a voluntary framework [28].

In the Netherlands, the distribution companies of gas, electricity, and district heating, established the Environmental Action Plan, in 1991, with the purpose of encouraging energy customers to save energy. Several measures were developed, such as, promotion of energy savings in space heating and lighting for non-residential buildings, housekeeping techniques for industry (information, advisory, and financial services), among others [29]. 
Part of the Environmental Action Plan, the Energy Efficiency Lighting Scheme (STIMEV) was a subsidy scheme open to nonresidential buildings that paid a levy for $\mathrm{m}^{3}$ of gas and $\mathrm{kWh}$ of electricity. The STIMEV promoted HF ballasts, mirror-optical armatures, PL armatures, lighting control systems, power reduction on existing installations. After 1992 the scheme was offered by distribution companies to their customers. Between 1991 and 1994 the STIMEV contributed to a reduction of 100,000 MWh. The scheme lasted until 2000 [30]. In 2008, a covenant More with Less that aimed at saving energy in the construction sector was signed by energy companies from the Netherlands, by the construction sector and the installation sector, and by the Energy transition platform for the built environment. There is a comprehensive set of measures that allows for considerable savings. In 2011, the implementation of the plan in about 500,000 buildings, would lead to an improvement of EE of 20 to 30\%. Approximately 300,000 buildings are expected to be added annually, starting in 2012 [31].

In Slovenia, the measure Financial incentives for efficient electricity consumption in the public sector has the aim of increasing efficiency in the use of electricity in public lighting, public utility services and other electricity uses in the public sector. Energy suppliers provide financial support for EE measures in lighting and other end uses. The measures started in 2008 and will last until 2016 [32].

In Switzerland, electricity suppliers offer advice and support to their customers, having developed special EE instruments and products [33].

Improvement of EE in public buildings and assets was targeted by World Bank projects in Croatia, in 2003, and in Macedonia in 2006. Both these projects targeted the creation of utility-based ESCOs. The Croatian Energy Efficiency Project received a US\$7 million grant from GEF $[11,34]$.

\subsection{American countries}

The non-mandatory involvement of utilities in the promotion of EE in several USA states is referred in the following paragraphs, namely Alaska, Alabama, Louisiana, Kansas, Mississippi, Missouri, North Dakota, South Carolina, South Dakota, Tennessee, and Wyoming.

A goal was set in June 2010 to reduce the per capita electricity consumption in the state of Alaska by 15\%, in 2020 that should be part of the utilities requirements under Energy Efficiency Resource Standards (EERS). EE programmes are voluntary and result from the initiative of the utilities. There are few programmes available for electricity customers. The Golden Valley Electric Association has been implementing EE programmes since 1992 [35,36]. The savings obtained in 2009, from measures implemented in the same year amounted to $965 \mathrm{MWh}$, which corresponds to $0.02 \%$ of the retail sales. For the same year, the state in the top of the ranking, Vermont, accomplished savings of $1.64 \%$ of retail sales [8].

In Alabama, the savings obtained in 2009 due to EE programmes promoted by electric utilities amounted to approximately $0.08 \%(63,382 \mathrm{MWh})$ of the sales, which is the result of the inexistent regulatory efforts to push the sole investor-owned utility (Alabama Power) to pursue EE on the demand-side. These amounts include the savings obtained from Tennessee Valley Authority (TVA). Utilities can recover lost revenues from EE programmes annually through a rate rider, although very little EE activities can be found [8,36,37].

In Louisiana, the Entergy New Orleans is the only utility in Louisiana to offer a portfolio of EE programs to its customers, and there is a tariff rider that depends on the savings accomplished. No investor-owned utility (IOU) reported any spending in EE programmes in 2008. In order to recover the programme costs, as well as for net lost revenues and a shared savings incentive, Southwestern Electric Power Company (SWEPCO) and Entergy have proposed an annual tariff rider. No EE programmes promoted by SWEPCO in Louisina were reported. As a matter of fact, Entergy has a rate rider that provides recovery of lost contribution to fixed costs. This rate rider can also provide performance incentives, compelling the utility to achieve the minimum of $75 \%$ of the target. The incentive cap is $125 \%$ of the annual projected savings goal $[36,37]$. No savings were reported from measures implemented in 2009 [8].

In Kansas, in 2007, producers were asked to reduce consumption by $5 \%$ by 2010 and by $10 \%$ by 2020 , without any EERS. Although EE programmes implemented by utilities are not required by law, both IOU and publicly-owned utility have been offering them. In 2010, the IOU budget for EE programmes was $\$ 5.4$ million, funded by customer rates. The Commission was considering the decoupling proposals on a case-by-case basis. Some incentives may be allowed but only for some particular programmes, such as: programmes for low and fixed income customers and renters, and proposals that demonstrate the potential for long-term savings using a whole house concept. Shared savings performance incentives can also be evaluated on a case-by-case basis $[36,38]$. The savings obtained from measures implemented in 2009 account for $971 \mathrm{MWh}$, which corresponds to approximately $0 \%$ of 2009 retail sales [8].

In Mississippi, utilities have no obligation to provide EE programmes. They may voluntarily offer their own but there are only a small number of programmes, with savings accounting for $31,188 \mathrm{MWh}$, only by $0.07 \%$ of the sales in 2009 . There was no cost recovery for the EE programmes [8,36,37].

Missouri has voluntary EERS. Electric utilities should achieve cumulative savings of $9.9 \%$ in 2020 (ACEEE, 2012). The EE programmes implemented in 2009 accomplished savings of $86,331 \mathrm{MWh}$, approximately $0.11 \%$ of retail sales in 2009 [8].

In North Dakota, there are no obligations for the implementation of EE programmes, although some utilities implement them voluntarily [38]. The measures implemented by utilities in 2009 accomplished savings of $2530 \mathrm{MWh}$, approximately $0.02 \%$ of retail sales in 2009 [8].

In South Carolina, all three IOU have been implementing EE programmes. The savings amounted to $46 \mathrm{GWh}$ (approximately $0.06 \%$ of sales) in 2009 . The Commission allows cost-recovery, a return on investment at least as high as supply-side measures, and ensures that utility net income is at least as high as it would have been without DSM measures. The cost-recovery is made on a case-by-case basis. Although not required by law, IOUs are submitting IRP with the incorporation of DSM and EE programmes. In South Carolina there are no EERS [8,36,37].

In South Dakota, utilities have been implementing EE programmes for the last 6 years. Both a cost recovery surcharge, to pay for DSM programs, and a performance incentive were approved. Lost revenue recovery mechanisms are also allowed. A voluntary objective was set in 2008 in order to achieve $10 \%$ of retail electricity sales from renewable and recycled energy sources by 2015. In 2009, the law permitted that "conserved energy" helped meet this objective. As a matter of fact, the spending in EE in South Dakota is minimal, due to some voluntary programmes implemented by utilities [36,38]. In 2009, 21,828 MWh of savings were obtained, which represented $0.2 \%$ of retail sales [8].

In Tennessee, Tennessee Valley Authority (TVA) has set internal goals, namely to reduce the load growth by $1400 \mathrm{MW}$ by the end of 2012, and lowering electricity capacity requirements by approximately $4 \%$ by 2012 . In 2010 , TVA set a new goal to achieve $3.5 \%$ of sales in energy efficiency savings by 2015 . TVA established 
partnerships with local municipal and cooperative utility distributors to deliver EE programmes [37]. The measures implemented by utilities in 2009 accomplished savings of $121 \mathrm{GWh}$, approximately $0.13 \%$ of retail sales in 2009 [8].

In Wyoming, utilities offer EE programmes despite not being obliged to. In order for the Commission to approve a DSM programme, utilities must provide evidence and justifications for the expected benefits. No state-wide study on the costeffective EE potential has been performed. In 2007 the Rocky Mountain Power completed a study on DSM potential and requested its update in 2010. Cost recovery is carried out on a case-by-case basis. Wyoming has approved a tracking adjustment mechanism that includes recovery of lost revenue for a small service territory covered by Montana-Dakota Utilities (MDU). The adjustment applies to all MDU customers to recover costs and lost revenues for load management programmes only. Rocky Mountain Power has no such adjustment. Performance incentives are not in place in Wyoming [36,35]. With the EE programmes implemented by utilities in 2009, savings of $7400 \mathrm{MWh}$, approximately $0.04 \%$ of retail sales in 2009 , were obtained [8].

Aside from the mandatory involvement of electric utilities in the promotion of energy efficiency in Brazil [39], during the 2001 power shortage, the Electropaulo, a local utility from São Paulo, distributed 4 million CFL to low-income customers as a measure to obtain instant effect on the load curve. The Electropaulo intentions were neither long-term market transformation nor cost reductions through efficiency [40].

In Mexico, the high efficiency lighting pilot programme intended to sell CFL at lower prices to residential consumers. The main target was low-income customers since they have heavily subsidized tariffs, paid by the utility. The economic return for the utility was larger for CFL installed in those costumers' households than in any other customer. The CFL were sold by the Mexican national electric company (CFE). Since the CFL were purchased by CFE in bulk, significant discounts over retail price were obtained. The customers could pay for the CFLs in full or in every electricity bill for a period of up to two years. Between 1995 and 1997, the CFE sold 2.5 million CFLs, high above the target of 1.7 million. After the end of the project, the price of CFL had fallen $30 \%$, and the distributors and retailers of CFL saw their sales increase. Although, this project was not designed to target a market transformation, the results indicate that there was a transformation of the market. A public/private non-profit organization, FIDE (Fidelcomiso para Ahoro de Energia Eléctrica-Trust fund for electric energy savings), together with the GEF continued this project. This project sold additional 4.8 million CFLs, across the country. This programme was also replicated to building insulation and air conditioning [14].

A mass distribution of CFL in Argentina, under the 2006 Argentina Energy Efficiency Project (AEEP) that received a $15 \mathrm{M} €$ GEF grant, was important to the utilities involved in the programme, which were obliged to sell electricity below the cost price. The participation of the GEF corresponded to $10 \%$ of the project costs, being the remaining financed by the Government of Argentina (46\%) and the utilities (44\%). Approximately 25 million CFLs were expected to be distributed by utilities to residential customers, in a three years period, replacing incandescent lamps. During this period the government had to support the conversion of an incandescent lamps factory to initiate the production of CFL. Some of the outcomes expected for 2010 were the increasing awareness about CFLs contribution for the reduction of electricity consumption; annual reduction of $2355 \mathrm{GWh}$; $1246 \mathrm{MW}$ peak demand reduction; and 1,290,000 $\mathrm{tCO}_{2 \mathrm{e}} / \mathrm{y}$. Besides utilities participation, this AEEP had also the objective of the development of the Argentina Energy Efficiency Fund. The Independent Evaluation Group of the World Bank believed that the results would have been much better if the CFL distribution was used to help increasing the tariffs $[11,41]$. The IFC/GEF Argentina Efficiency Street lighting Programme, between 1999 and 2001, targeted introduction of energy efficient SL technology in public lighting [42].

In 1998, the USAID provided technical assistance to the Costa Rica Institute of Electricity (Instituto Costariccense de Electricida$d$-ICE) in the development of a load management project, aimed at reducing the peak loads, targeting intensive industrial and commercial electricity consumers. This project emerged from the need to deal with increasing demand associated with difficulties in making new investments. In accordance with the Rational Energy Use law, the Law 7447 of 1994, electricity utilities and the Ministry of Energy and Environment (MINAE) had to implement energy efficiency programmes targeting intensive electricity consumers [43]. In 2008 the Efficient Lighting Programmes Three-fortwo Promotion for Compact Fluorescent Lightbulbs targeted residential consumers that were offered to buy three CFLs for the price of two. The goal of this project was to save $30 \mathrm{MW}$ and an investment of US\$ 30million in fuel during the CFL lifetime [44].

In 2004 in Uruguay, a World Bank project targeted energy efficiency in public lighting, with the participation of utilities, being the EE equipment financed through electricity bills for the government sector. The Uruguay Energy Efficiency Project, received a grant of US\$6.88million from GEF and intended to develop regulations to support DSM, provide assistance to the integration of EE in the energy strategy of the country, appliance testing, labelling and standards development [11,34].

The Efficient Light Initiative (ELI) programme (1997-2009), financed by the GEF, actually applied not only in the American continent, was implemented in two tranches. Tranche I included Argentina, Peru, and South Africa, and tranche II included the Czech Republic, Hungary, Latvia, and the Philippines. Electric utilities implemented some of ELI activities, such as selling and financing energy efficient lamps to their customers, in Argentina, Peru, the Philippines, and South Africa $[14,45]$. In Argentina, a pilot project implemented in low-income households, lead to a $20 \%$ bill reduction due to CFL-generated savings, and to a reduction of $35 \%$ in non-payment of bills. Due to these results, utilities had extended these offerings to $60 \%$ of residential consumers. As a matter of fact, by reducing electricity costs, ELI was considered a success and used as a reference by allowing more electricity services to the communities, mainly those struggling with fewer resources. Another positive effect of ELI was the increase in the load factor of the Peruvian electrical demand, since 1999, from 0.7 to values between 0.8 and 0.82 [46]. South Africa was also suffering from power shortages for more than a decade, but emerged as a national crisis in 2008. DSM alternatives are one of the measures that Eskom was using to face the crisis and reduce consumption while building more capacity. Some of the major DSM measures were CFL replacement programmes and installation of smart meters that allow demand control [2].

\subsection{Asian countries}

The Thailand Promotion of Electrical Energy Efficiency Project (TPEEEP), with the involvement of the Generating Electric Authority of Thailand (GEAT), the national electric utility, received a grant from GEF, between 1993 and 1998, to change the market for energy-consuming products, such as lighting. This project included the labelling of appliances, building certification, and public education [11]. Since 1996, even without any legal mandate, the EGAT has been running a voluntary energy labelling covering several end-use equipment [47].

In Vietnam, the national utility, Electricity of Vietnam (EVN) carried out, since 2001, programs to promote the use of energysaving lighting equipment, such as CFLs and thin-tube, "T8" 
fluorescent lamps. Under the 2006-2010 Energy Savings Program, 40 million incandescent lamps should be replaced by CFLs, FTLs, and T5 lamps, been EVN a part of this project [47].

In Sri Lanka, a privately-owned distribution company, the Lanka Electricity Company, was partner with the Ceylon Electricity Board (CEB), the vertically integrated public utility, in a DSM programme to deal with power crisis of the 1990s. The Energy Conservation Fund also collaborated with the implementation of this programme in the public sector. This programme aimed to reduce the peak load and the energy demand, through the sale of CFL to utility customers. CFL were then paid during a 12 month period, through an item in the electricity bill. The number of lamps sold to participants was 261,000 and the number of CFLs purchased by non-participants was almost five times higher $(1,235,000)$. This programme was in place between 1994 and $2001[4,48]$.

In 2009, The World Bank financed the Efficient Lighting Initiative of Bangladesh (ELIB). This project consisted of a largescale replacement of incandescent bulbs by CFL in order to reduce the impact of peak load deficits and poor level of electricity service. Through the substitution of 10 million lamps to residential customers the project would contribute to the reduction in peak power demand and load shedding [49].

In India, between 1997 and 1998, a pilot project on promoting EE in pumping systems was delivered by the Ahmedabad Electricity Company (AEC). The project was implemented by AEC and the Ahmedabad Municipal Company. Other programmes, addressing water pumps, time-of-use meters, motors, and energy audits, among others, were implemented by AEC, with funds from the USAID, between 1995 and 1997. Also, the improvement of efficiency in pumping systems in the agricultural sector was promoted by the Noida Power Company Ltd (NPCL), between 2001 and 2002 [48]. In 2001, the USAID assisted the government with the Energy Conservation and Commercialization (ECO) project that intended to support the promotion of EE technologies and services by the Indian utilities. Also the World Bank supported DSM programmes as part of the reform strategy in states like Orissa, Haryana, Rajasthan, and Andhra Pradesh, although the implementation was very slow due to administrative and institutional barriers [50]. In 2005, a pilot programme was conducted by the Bangalore Electricity Supply Company (BESCOM) to replace incandescent lamps by CFL, in the residential sector. "BESCOM partnered with International Institute for Energy Conservation supporting the Bureau of Energy Efficiency under a bilateral funding from USAID." [48].

In the Philippines, in 1996, the Cagayan Electric Power and Light Company (CEPALCO) promoted a demonstration programme of energy efficient equipment and plant practices in order to improve efficiency in the industrial sector, providing $75 \%$ of the cost of equipment. CEPALCO received a grant from the USAID. Other DSM programmes of CEPALCO were based in CFL, in high efficient fluorescent lighting, energy audits to commercial and industrial customers, industrial demonstration programmes [48]. Another DSM experience in the Philippines was the ELI programme, referred in Section 2.2.

Although most of those projects were successful, the lack of political engagement did not allow the experiences to work as starting points for the sustainability and durability of DSM programmes. The TPEEEP project was considered quite successful as a market transformation one. During the project period, the government allowed a tariff charge to finance the project. After that, the EGAT started funding DSM initiatives through their regular tariff revenue, since they found DSM programmes to be worthwhile in their ability to improve EGATs public image. A DSM office was created within the utility. But the funds eventually decreased. Then, DSM was encouraged by the government but not required by regulations, nor were funds attributed to DSM programmes. A similar situation could be found in Vietnam. In accordance with Vietnamese regulations, the government has to consider DSM but there seems to be no imposition for the utilities to invest in DSM $[2,11,51]$. Some studies were conducted in Oman that concluded that despite the high potential for DSM and energy conservation measures there has been no corresponding governmental effort to promote them [52]

\subsection{African countries}

The support given to Botswana by the World Bank was an answer to the rapid electricity growth, expansion of the mining sector, and a lagging investment in generation and transmission. The Botswana Power Company (BPC), a vertically publicly owned utility, implemented the National Energy Efficiency Campaign (NEEC). This campaign included bulk procurement and distribution of CFLs, load control of electric water heaters, awareness and promotional campaigns, and large customers conservation programme (including demand management and cogeneration retrofits) [2].

In Uganda the power shortage began in 2004 due to a severe drought, reducing the hydropower generation capacity. With the intervention of the World Bank, DSM measures, including loss reduction and bulk replacement of CFLs, were implemented. The CFL programme started with a survey that demonstrated that only $1 / 3$ of the households were using efficient lighting solutions. This survey was followed by an awareness campaign and 800,000 CFL were produced and distributed. For each household, three CFLs were given, by the state utility, in return for three incandescent bulbs. The cost of the CFL programme that resulted from the evaluation was $1 / 10$ th of the cost of electricity from diesel-fired generation [2].

The World Bank approved a project in Central African Republic, where 100 thousand CFL bulbs were distributed as a strategy to avoid more expensive power generation and fight against poverty [2].

Utility DSM education and investments in public administration buildings programmes were given support by a World Bank project regarding the power sector development in Burkina Faso, in 2004. This started with pilot cases in the public administration before expanding to other sectors $[11,34]$.

South African experience with the ELI programme and the involvement of Eskom in DSM, was referred in Section 2.2.

\subsection{Australasian countries}

In New Zealand, the Energy Efficiency Conservation Authority (EECA) is responsible for the promotion of energy efficiency, the preparation of regulatory acts, such as minimum energy performance standards, labelling, and disclosure of information to compile statistics. The IEA, in the most recent review on energy policies in New Zealand, suggests that the involvement of utilities in EE promotion should be fostered [53]. Nevertheless, ripple control of water heaters has been used as a strategy to accomplish the DSM objectives of peak clipping and load shifting. Deferment of investment in new capacity is the main motivation for utilities to adopt this strategy [54]

Between 1993 and 1996, DSM potential assessment studies were conducted in ten Pacific Island utilities, under the UNDP funded project Support to the Pacific Islands Power Sector. Nine DSM programmes involving CFLs, high efficiency fluorescent lighting, refrigerator labelling and standards, air conditioner labelling and standards, commercial refrigeration equipment maintenance, air conditioner equipment maintenance, interruptible rates for large customers, energy audits for large customers, 
and air conditioner timer control were identified and considered suitable to be implemented in the Islands. A second project, that aimed the implementation of DSM pilot projects, was funded by the United Nations Department of Economic and Social Affairs (UNDESA), in 2003 [48].

In the Fiji Islands, a pilot DSM project promoted by the Department of Energy of the US and the Fiji Electricity Authority (FEA) was intended to train FEA staff to identify EE measures addressing commercial and industrial customers. The project also aimed the reduction of the peak demand by assisting FEA with the promotion of DSM to electricity intensive consumers. This training took place from 2 to 13, February, 2004 [55].

Two demand-side management workshops, promoted by the global sustainable electricity partnership, aimed the training of utilities engineers from the Southern Pacific Islands (in 2009) and Northern Pacific Islands (in 2010). Utilities from the Island States of Cook, Fiji, Kiribati, Niue, Papua New Guinea, Samoa, Solomon, Tonga, Tuvalu, participated in the 2009 workshop. Also, Engineers from utilities from the Island States of Guam, Palau, Marshall Islands, American Samoa, Northern Mariana Islands and five of the Federated States of Micronesia, participated in the 2010 event [56].

\section{The Portuguese case-study}

In 1998, the first regulatory framework was approved that fosters the involvement of electric utilities in the promotion of EE on the demand-side.

An ordinance from 2002, states that the Energy Services Regulatory Entity (ERSE) should, among other things, contribute to the improvement of technical, economical, and environmental conditions, and stimulate the adoption of behaviours that lead to a more efficient use of energy. The restructuring of the electricity market, together with regulatory evolution, has fostered the improvement of the supply-side efficiency. However, there are barriers that prevent the increase of the efficiency on the demand-side, namely to the promotion of EE on the demandside by electric utilities [57].

Under the Kyoto Protocol, Portugal accepted the commitment to limit the increase of GHG emissions by $27 \%$ of the amount in 1990 for 2008-2012. The Portuguese Climate Change National Plan (PNAC) quantifies the national effort in the context of diverse policies and measures over all activity sectors. The development of mechanisms for the promotion of energy efficiency on the demand-side, with the main goal of the reduction of electricity consumption by 2010 was assigned to ERSE by PNAC [58].

A national strategy for energy promotes, among other things, energy efficiency in both the supply- and demand-side. Among several strategies, the fourth guideline - Energy Efficiency Promotion - establishes several measures to be adopted, such as the Promotion of energy efficiency policies by electricity suppliers and Fund energy efficiency promotion actions. In this framework the National Energy Efficiency Action Plan (PNAEE): Energy Efficiency 2015 was approved. The PNAEE sets a target to be achieved by 2015 through energy efficiency measures with an improvement of $10 \%$ in final energy consumption.

In 2009, the European Directive no. 2006/32/EC on energy enduse efficiency and energy services was made a national law. Under this law, a target of 9\% energy savings until 2016 was set to be achieved through the implementation of an action plan for energy efficiency improvement.

In 2010, the National Strategy for Energy 2020 (ENE 2020) was established. This strategy sets a savings target of $20 \%$ in final energy consumption by 2020 , highlighting the contribution of behavioural and tax measures, innovative projects, mainly electric vehicles and smart girds, distributed generation based on renewable sources and the optimization of public lighting models and of energy management in public buildings, households and services.

\subsection{Demand-side management plans}

The tariff regulation code approved in 1998 established that the costs associated to demand-side projects were to be included in the revenues from the tariffs applied to electricity consumption. This methodology was initially applied to the first regulatory period, between 1999 and 2001. The 2001 Tariff regulation [59], imposed that supply tariffs of the public electricity system provided revenues that should include reimbursement of the costs associated to demand-side programmes, as well as $50 \%$ of the associated benefits. The public electricity distributors were required to present Demandside Management Plans (PGP_Planos de Gestão da Procura) for each year of the regulatory period. These PGP contained a set of measures to promote $\mathrm{EE}$ in consumption that should be implemented in each year of the regulatory period. These rules were applied from 2002 to 2004 and in 2005. Due to uncertainties regarding the regulatory evolution following the reform of the electricity sector, the PGP was maintained only during 2005 , as a transitory period. The measures could target residential consumers, services sector, industrial consumers, or public lighting. The criteria used for the selection of the residential and services sector measures were the potential for consumption reduction and the improvement of the load diagram. For the residential sector measures that promoted the use of more energy efficient refrigerators and freezers, CFLs, and heat accumulators were allowed. For the services sector, measures involving electronic ballasts and efficient lamps, power factor correction, and heat pumps were accepted. In public lighting, measures to change lamps and lamp fixtures were suggested. For the industrial consumers, measures that regarded EE improvement in motors were privileged, since $75 \%$ of electricity consumption is estimated to be due to electrical motors and drives. The allowed measures involved high efficiency motors, variable speed drives, and power factor correction. Besides these tangible measures, intangible measures were also allowed, which did not address any particular equipment, but were more global, addressing the way energy was consumed, such as with informative campaigns, training, and characterization studies $[60,61]$.

\subsection{Demand-side efficiency promotion plan (PPEC)}

Several circumstances such as barriers in the acquisition of efficient equipment and in more energy efficient habits by consumers, as well as environmental externalities not reflected in the energy prices, hamper the improvement of energy efficiency. These circumstances justify the implementation of measures that promote efficiency in energy consumption as well as stimulate energy efficient products and services. Among the market barriers in the implementation of EE highlighted in the regulatory framework from 2008 (hereafter 2008 Rules) are: long return on investment periods, the difference between the supply prices, or the applicable tariffs, and the short-term marginal costs, externalities, lack of information and high associated transaction costs, misaligned interests between actors, and customers financial restrictions [57].

Under the regulator statutes there is the obligation to improve the environmental performance of companies in the energy sector and to contribute to a more efficient use of resources, which led ERSE to launch the demand-side efficiency plan (PPEC). PPEC rules were published in 2006 and improved two years later, in 2008. Some improvements were made in 2010 , under the same regulatory framework.

Restricted to electricity, PPEC has the objective of promoting measures intended to improve efficiency in electric energy 
consumption, through actions taken by electricity suppliers, distribution and transport network operators, consumer organizations, business associations, energy agencies, higher education institutions, and R\&D institutions. These actions target energy customers from different sectors, and are subjected to a selection procedure, whose criteria and corresponding weights are defined in PPEC rules. The plan is implemented through a tender mechanism that allows the selection of the "best" EE measures to be implemented by their promoters, and partially funded by PPEC's budget.

The measures proposed to this mechanism should promote the reduction of electricity consumption or load management (LM) actions, on a permanent and accountable basis. The energy consumption reduction effect of the measures cannot have been accounted for in any other specific measures. Information disclosure measures may qualify, despite not having accounted for impacts, as they may promote more rational behaviours and awareness, and allow informed decisions to be taken regarding the adoption of more energy efficient solutions. It is expected that the benefits of these actions remain long after the measure itself, therefore it is important to reach as many customers as possible in order to increase the spill over effect of the incentives.

Since PPEC budgets are limited, the approved measures should be those that would probably not be implemented without the incentive given by PPEC, thus contributing to eliminate a market barrier.

Regarding the type of promoters, there are two different tendering. One accepts measures proposed by all types of promoters, and the other only allows promoters that are not electric utilities. This distinction allows other actors to enter the tender, not included in the electricity sector, increasing the number of winning proponents. On the other hand, many of the proponents are regional institutions, with greater proximity to customers and to a different target audience that can be reached by companies that operate at a national level. Each non-utility promoter must choose between the two tenders. In order to allow a larger number of actors to be involved, two restrictions were imposed: the maximum amount allowed for each candidate measure is one sixth of the total budget in that tender, and each promoter can only have two winning measures. Tendering for entities that are not electricity sector agents were created by the 2008 rules. Regarding the tendering for all promoters, another restriction was also created by the same regulatory framework, which sets the maximum amount to finance a measure to one third of the budget of the respective tendering. Previously, there was no limitation.

In the tender for all promoters, the main goal is to maximize the economic benefits. In the tender for non-utilities some restrictions are imposed in order to increase the value of the spill over effect and the share of the benefits, by reducing the value of the economic benefit and the possible hoarding of available funds.

Two types of measures are allowed: Tangible or "hard" and Intangible or "soft" measures. The tangible measures are those related to the installation of equipment with energy efficiency levels above the market standard. Intangible measures are those related to the disclosure of information regarding efficient use of electricity aimed at more energy efficient consumer behaviours. Some examples of intangible measures are training courses, information disclosure campaigns, and energy audits.

Table 1

Number of promoters, number and costs of the measures implemented in the PGP of 2002-2004 and 2005

Source: [62].

\begin{tabular}{lcc}
\hline & $2002-2004$ & 2005 \\
\hline Number of promoters & 1 & 1 \\
Number of measures (intangible) & 12 & 11 \\
Total cost of the measures (millions of euros) & 1.1 & 2.4 \\
\hline
\end{tabular}

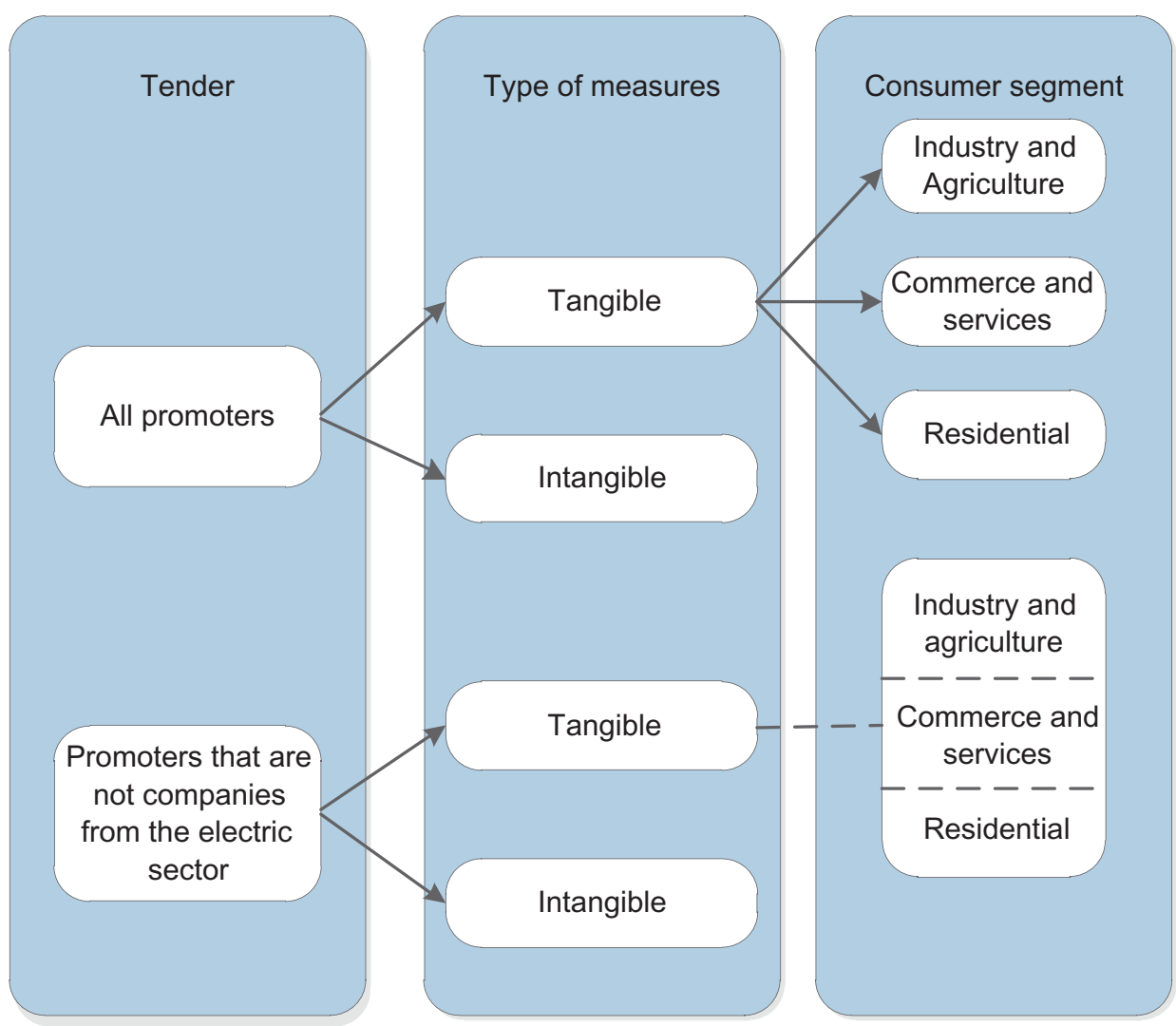

Fig. 1. Tenders, type of measures and consumer segments in PPEC (adapted from [58]). 
Tangible measures are classified by consumer segment. The financial incentive is divided among segments, ensuring that all consumer segments can receive incentives from PPEC. On the other hand, since the financial incentives of PPEC come from a charge paid by all electric energy customers, it is important to ensure that all customers benefit from the measures funded by PPEC. The consumer segments are Industry and Agriculture, Commerce and Services, and Residential. Tangible measures in the tender for all promoters are ranked within the consumer segment they are addressed to. The result will then be three ranked lists of measures, one for each consumer segment. In the tender for non-utilities, the measures are not separated by consumer segment. The result will be a single list with the measures addressed to the consumer segments. Intangible measures are ranked in each tender, resulting in two more lists of measures. In all lists, measures are ranked in decreasing order of merit. The total costs of intangible measures can be financed by PPEC. The 2008 rules imposed a limitation for tangible measures, where only $80 \%$ of the total cost of the measure can be paid by PPEC.

The tenders are presented in Fig. 1, with the type of measure in each tender and the consumer segment for each type of measure, resulting in six different tenders.

The PPEC calls for proposals are a biennial event, where intangible measures can have an implementation period of one or two years and those that are tangible must be implemented in two years. This was a change introduced by the 2008 rules. Previously, the measures could be implemented for a period of up to three years. Since the calls were annual, this was inconvenient because measures from three different PPEC editions could coexist in the same year.

\subsection{Utilities participation in the PGP and PPEC editions}

\subsubsection{Demand-side management plans (PGP)}

The PGP was applied to the only electricity supplier. Although tangible measures were allowed, only intangible ones were implemented (Table 1 ).
The type and costs of the PGP implemented measures are presented in Table 2 . The EE studies implemented were mostly characterization of consumers and networks, and ownership and use of electric equipment in the service sector.

Some of the measures implemented between 2002 and 2005 were:

- EDP awards - an incentive for the adoption of measures and processes that minimize energy costs in industry and services. These awards were implemented since 1989, by EDPDistribuição (distribution company) with positive results.

- Characterization of consumers and networks - this measure aimed at updating the typical consumption profiles of diverse low voltage consumer classes. These profiles are then used to define timely profiles for the energy to be acquired by retailers.

- Discovery of adjustment factors for losses - this study aimed to establish adjustment factors for losses by voltage level and time of use period in transport and distribution networks.

- Ecocasa - this measure consisted of the presentation and disclosure of a virtual model that intended the promotion of energy efficiency in the household sector, focusing on lighting, air-conditioning, and appliances. The measure also intends to promote construction solutions that reduce the electricity consumption needs.

- Promotion of energy efficient equipment - this measure intended to disclose and promote ceramic heat storage, together with time-of-use tariff. With this measure a reduction of consumer energy bills, and peak power demand was expected.

- Usage habits of electrical equipment in the services sector - A study from EDP-Distribuição with the aim of characterizing service customers regarding their economic activity and equipment ownership.

- Disclosure of information on rational use of electrical energy (RUEE) - a set of measures that targeted raising awareness of EDP-Distribuição customers about the benefits of RUEE.

Table 2

Type and costs (in thousands of euros) of PGP implemented measures between 2002 and 2005.

Source: [61].

\begin{tabular}{|c|c|c|c|c|}
\hline Measures & 2002 & 2003 & 2004 & 2005 \\
\hline EE studies & 205 & 325 & 164 & 449 \\
\hline Promotion of EE equipment & 41 & 36 & 130 & 120 \\
\hline Disclosure of information on rational use of electric Energy & 34 & 83 & 0 & 1812 \\
\hline Others & 24 & 0 & 0 & 0 \\
\hline Total & 334 & 443 & 295 & 2381 \\
\hline
\end{tabular}

Table 3

Expected budget amounts for each PPEC edition (millions of euros).

Sources: $[58,62-64]$

\begin{tabular}{|c|c|c|c|c|}
\hline & 2007 & 2008 & 2009-2010 & 2011-2012 \\
\hline Intangible measures (all promoters) & 2.0 & 2.0 & 3.5 & 3.5 \\
\hline \multicolumn{5}{|l|}{ Tangible measures (all promoters) } \\
\hline - Industry and agriculture & 3.0 & 3.0 & 5.8 & 5.8 \\
\hline - Commerce and services & 2.5 & 2.5 & 4.9 & 4.9 \\
\hline - Residential & 2.5 & 2.5 & 5.3 & 5.3 \\
\hline Intangible measures (non-electricity sector companies) & - & - & 1.5 & 1.5 \\
\hline Tangible measures (non-electricity sector companies) & - & - & 2.0 & 2.0 \\
\hline Total & 10.0 & 10.0 & 23.0 & 23.0 \\
\hline
\end{tabular}


The measures included were: a website on energy efficiency, an energy efficiency guide, a Road-Show in schools, the distribution of a leaflet together with the electricity bill, and an awareness campaign on energy efficiency.

The participation in the PGP seems to have fallen short of expectations, in regards to the participation of the utility in promoting DSM programmes, namely because no tangible measures were implemented.

\subsubsection{Demand-side efficiency promotion plan (PPEC)}

As previously stated, the PPEC editions of 2007 and 2008 were annual and the following started to be every two years (20092010 and 2011-2012 editions). The expected budgetary amounts available for each PPEC edition are presented in Table 3.

Comparing the expected budget amounts for each PPEC edition (Table 3 ) with the cost of proposed measures (Table 4), it is possible to see the high level of participation, a clear sign of the success of the PPEC mechanism.

The participation of the promoters, utilities and non-utilities, in PPEC editions has been changing. Although the participation in relative terms has been decreasing (Table 5), the number of utilities that participated in the last PPEC edition is above half the number of suppliers and distributors operating in Portugal, which is presently twenty two [65]. Both the increasing number of participating utilities and non-utility type of entities is an indicator of the importance and success that this mechanism has accomplished.

Besides the number of participating agents, the number of measures proposed has been increasing and is also an indicator of the importance that the promoters assign to this mechanism. Since some of the proposed measures were not eligible due to the violation of one or more of PPEC rules, the eligible and approved measures have been analysed. The number of eligible measures proposed by utilities have increased until 2009-2010 but decreased in the last PPEC edition. On the other hand, the number of eligible measures by non-utilities more than doubled from the 2009-2010 to the 2011-2012 edition (Table 6).

The reduction of measures from utilities is mostly due to a decrease in the number of intangible measures (Fig. 2). The number of tangible measures considered eligible has been increasing, and so has the number of approved measures. In the last PPEC edition, more than half the number of eligible tangible

Table 4

Costs of the measures candidates to each PPEC edition (in millions of euros). Sources: [58, 62-64].

\begin{tabular}{lrrll}
\hline & 2007 & 2008 & $2009-2010$ & $2011-2012$ \\
\hline Eligible proposed measures & 27.0 & 56.0 & 58.1 & 57.1 \\
Intangible measures & 7.3 & 8.7 & 18.2 & 18.3 \\
Tangible measures & & & & \\
$\quad$ - Industry and agriculture & 4.2 & 7.3 & 10.5 & 7.5 \\
$\quad$ - Commerce and services & 8.3 & 17.2 & 16.5 & 19.7 \\
$\quad$ - Residential & 6.8 & 13.0 & 12.8 & 11.6 \\
\hline
\end{tabular}

Table 5

Electric utilities participation in each one of the PPEC edition.

\begin{tabular}{lll}
\hline $\begin{array}{l}\text { PPEC } \\
\text { edition }\end{array}$ & $\begin{array}{l}\text { Number of utilities/number of } \\
\text { promoters }\end{array}$ & $\begin{array}{l}\text { Number of utilities } \\
(\%)\end{array}$ \\
\hline 2007 & $6 / 8$ & 75 \\
2008 & $10 / 21$ & 48 \\
$2009-2010$ & $11 / 29$ & 38 \\
$2011-2012$ & $12 / 48$ & 25 \\
\hline
\end{tabular}

Table 6

Number of eligible measures by utility and non-utility promoters.

\begin{tabular}{lrrrr}
\hline & 2007 & 2008 & $2009-2010$ & $2011-2012$ \\
\hline Utilities & 58 & 81 & 85 & 72 \\
Non-utilities & 4 & 32 & 36 & 74 \\
& 62 & 113 & 121 & 146 \\
\hline
\end{tabular}

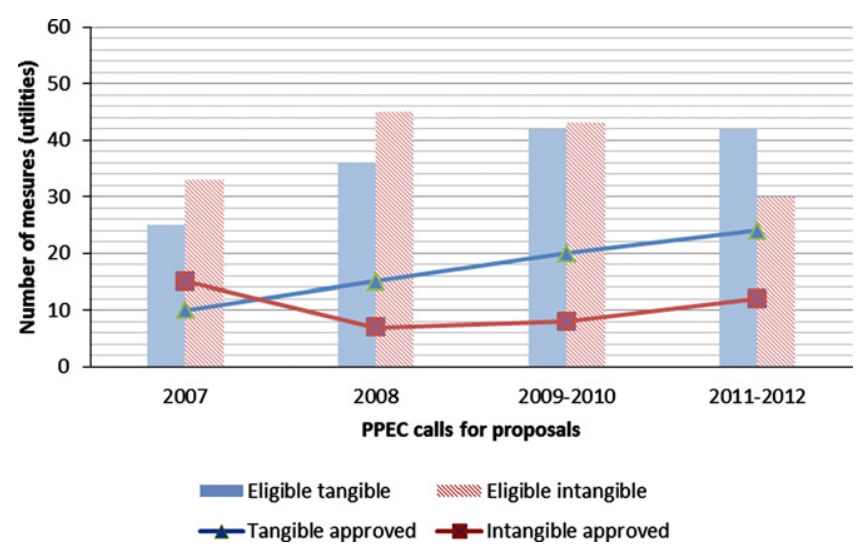

Fig. 2. Number of eligible and approved measures proposed by utilities for each PPEC calls for proposals.

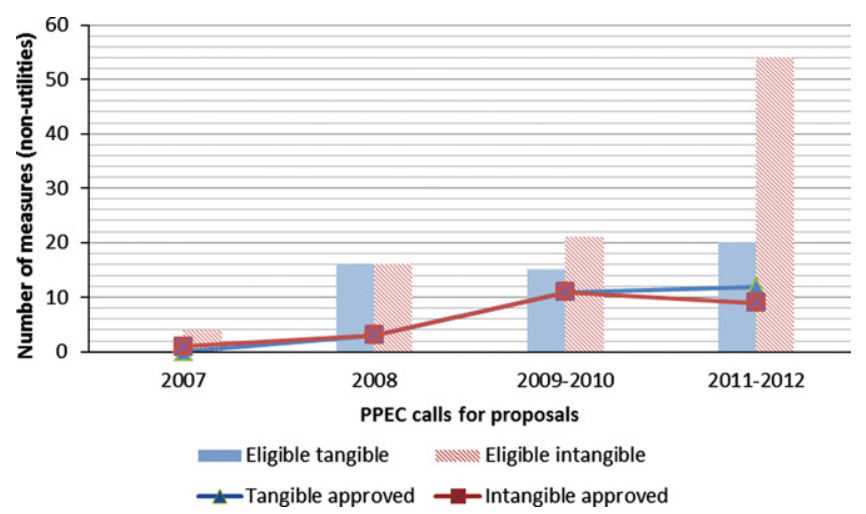

Fig. 3. Number of eligible and approved measures proposed by non-utilities entities, for each PPEC edition.

measures was approved. Although the number of eligible intangible measures has decreased, the total number of approved measures increased.

Regarding the measures proposed by non-utilities, there seems to be a preference for intangible measures (Fig. 3), mainly in the last PPEC edition, where the number of eligible measures more than doubled, compared to the number of measures from the previous edition. The existence of a tender for agents that are not utilities, since the 2009-2010 edition, has granted to these entities the approval of a relatively important number of measures. Eight out of eleven tangible measures approved in 20092010, were candidates for the tender for non-utilities. In the 2011-2012 edition, from the twelve tangible measures approved, six were from that same tender. On the other hand, in the last PPEC edition, eight out of the nine intangible measures approved were candidates for the non-utilities tender. A similar situation had happened in the previous PPEC edition, where only one of the approved measures was a candidate for all the proponents' tender.

Although there has been a slight increase in the number of tangible measures proposed by non-utilities in last PPEC call 
(Fig. 3), the average societal cost of each approved measure is almost three times higher in the last one than the previous (Fig. 4). Regarding the utilities participation, the average societal cost of the approved measures decreased in the last PPEC, against the increasing tendency seen in the previous calls. As for the intangible measures, the average costs are, as expected, lower when compared with the average costs of the tangible measures.

For the last two PPEC editions, the PPEC share in the costs of tangible measures is capped at $80 \%$ of the total costs. This resulted in an increase in the promoters' share of the costs that can be seen in Fig. 5. In the last PPEC edition, the utilities contribution was 6\% of the costs, approximately 2.3 million euros. On the other hand, PPEC may finance all intangible measures costs supported by the promoters.

The more frequent types of measures proposed by utilities are related to efficient lighting (Table 7). The improvement of energy efficiency in motors and drives has also received some attention from the utilities, mainly in the last PPEC call.

Regarding non-utility proponents, measures targeting lighting and the motors and drives are among the most selected (Table 8).

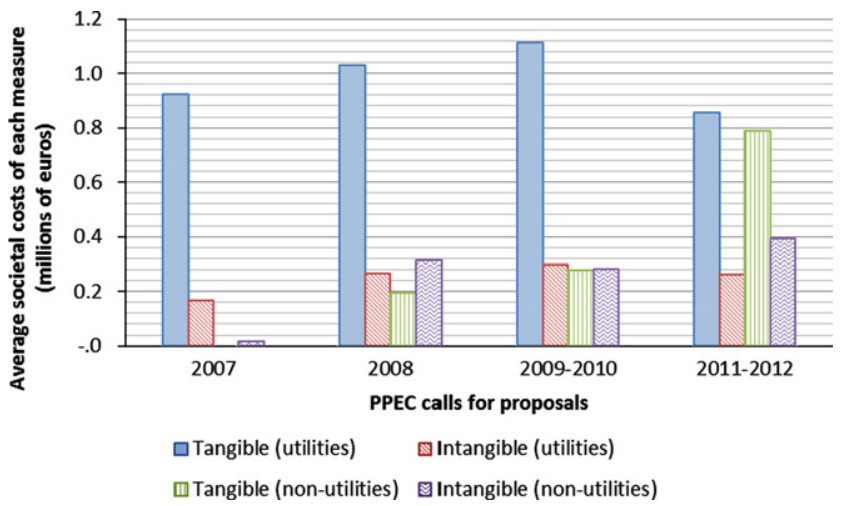

Fig. 4. Average societal costs of the measures approved in each PPEC edition.

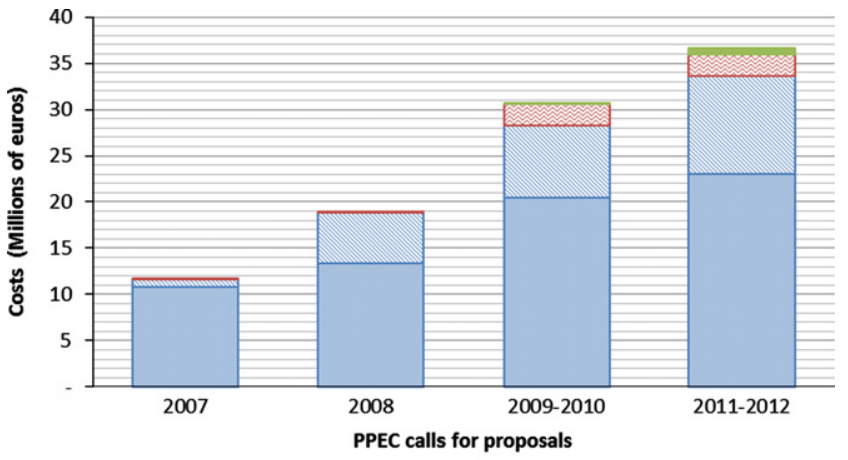

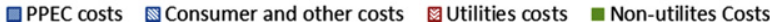

Fig. 5. Costs of the several PPEC editions distributed by PPEC, Consumers and other costs, and proponents (utilities and non-utilities).

Table 7

Number of approved measures promoted by utilities, by the more frequent type of end-use, in each PPEC edition.

\begin{tabular}{lllll}
\hline End-use & 2007 & 2008 & 2009-2010 & 2011-2012 \\
\hline Lighting & 6 & 6 & 13 & 13 \\
Drives and motors & 1 & 3 & 2 & 7 \\
Refrigeration & 1 & 1 & 4 & - \\
Power factor correction & 2 & 3 & - & 1 \\
\hline
\end{tabular}

Table 8

Number of approved measures promoted by non-utilities, by the more frequent type of end-use, in each PPEC edition.

\begin{tabular}{lllll}
\hline End-use & 2007 & 2008 & $2009-2010$ & 2011-2012 \\
\hline Lighting & - & - & 9 & 6 \\
Drives and motors & - & 2 & 2 & 2 \\
Refrigeration & - & - & - & 1 \\
Power factor correction & - & - & - & -
\end{tabular}

The preference for efficient lighting measures occurred in Portugal, and also in other countries, is due to the high costeffectiveness associated with these measures.

According to ERSE estimates, the savings obtained by all PPEC editions will correspond to $1.2 \%$ of 2013 Portuguese consumption [66].

\section{Conclusion}

The involvement of electric utilities in the promotion of EE has already more than three decades. The evolution of the electricity sector towards unbundling and de-regulation caused the financial and economic interests of electric utilities (privately-owned or co-existing with publicly-owned) to become an important, almost decisive, issue in energy planning decisions. The pressure to obtain short-term profits caused situations where the utilities objectives were hardly in line with societal objectives. Increasing energy efficiency would reduce utilities revenues in the shortterm, causing a strong disincentive for utilities to foster EE on the demand-side. However, there are currently utilities in many parts of the world actively engaged in EE programmes, only less than two decades after the liberalization boom. The evidence of higher levels of savings when utilities are under savings obligations schemes, suggests that EE obligations are an effective mean to deal with the motivation of utilities to promote energy savings. Nevertheless, many utilities promote EE without any obligation or participate in DSM experiences funded under international cooperation projects. These projects usually intend foster the involvement of utilities and governments in DSM.

Most of the experiences reported in this paper indicate that the non-mandatory participation rarely produces amounts of energy savings comparable to more committed situations.

In the Portuguese case, although the involvement of utilities in the promotion of DSM has been regulated for fifteen years, a stronger commitment has only been seen in the last five or six years. The regulator has developed a structured approach to adapt the regulatory framework, using previous experience and the information gathered through public consultation by other entities interested in this subject.

The promotion of EE on the consumer side has been mostly boosted by the Portuguese regulator, firstly with the PGP and then by the PPEC mechanism. In the PGP, although the costs of the measures were recovered by the promoters and the benefits where equally shared between the promoter and the consumers, only intangible measures were implemented.

EE fostering by utilities was then redeemed in 2007, with voluntary participation by utilities, under the PPEC mechanism. Only the recovery of the costs was allowed, for the 2007 and 2008 PPEC editions. After that, only $80 \%$ of the costs of the tangible measures can be recovered. Even knowing that the EE programmes would contribute to a reduction in revenues, the participation of utilities has increased. Nowadays, not only are lost revenues not addressed but neither is the total cost of the measures fully paid by PPEC funds. Utilities are investing in programmes that reduce their revenues. In a competitive environment this is an apparent paradox. 
Nevertheless, they keep participating in the programme, probably driven by the expected improvement of their public image [66]. However, more innovation will soon be necessary, which will certainly be costly. Looking for broader approaches for the promotion of EE, besides lighting technology replacement, was the road taken by utilities with longer experience.

According to Apolinário et al. [66], the involvement of several actors in the promotion of EE, as in the Portuguese case, with the participation of utilities, consumers associations, universities, etc., will hardly be accomplished under EE obligations. On the other hand, Waide and Buchner [47], consider that the evidence of higher levels of savings when utilities are under savings obligations schemes, suggests that EE obligations are an effective mean to deal with the motivation of utilities to promote energy savings. Under savings obligations, utilities will try to promote the measures/programmes with higher cost-effectiveness, in order to reduce their costs. Although utilities voluntarily engage in the promotion of EE measures on the demand-side, better results may be achieved with a regulatory framework that defines savings mandatory targets, provides budgetary amounts in line with the savings goals, and acknowledges the need for a framework that allows utilities revenues to be less dependent on energy sales.

\section{Acknowledgments}

This work has been partially supported by FCT under project grant PEst-C/EEI/UI0308/2011.

\section{References}

[1] Steinberger J, Jv Niel, Bourg D. Profiting from negawats: reducing absolute consumption and emissions through a performance-based energy economy. Energy Policy 2009 2009;37:361-70.

[2] Heffner G, Maurer L, Sarkar S, Wang X. Minding the gap: World Bank's assistance to power shortage mitigation in the developing world. Energy 2010;35:1584-91.

[3] Nowak S, Kushler M, Sciortino M, York D, Witte P. Energy efficiency resource standards: state and utility strategies for Higher Energy Savings. Washington, D.C.: American Council for an Energy-Efficient Economy; 2011.

[4] Taylor RP, Govindarajalu C, Levin J, Meyer SA, Ward WA. Financing energy efficiency lessons from Brazil, China, India, and Beyond. Washington D.C.: The World Bank; 2008.

[5] Swanson S. Regulatory mechanisms to enable energy provider delivered energy efficiency. Montpelier (Vermont-US): regulatory assistance project; 2012.

[6] Sousa, JL, Martins, AG, Jorge, HM. Dealing with the paradox of energy efficiency promotion by electric utilities, In: Seventh conference on Sustainable Development of Energy, Water and Environment Systems-SDEWES conference, Ohrid; 2012.

[7] Molina M, Neubauer MSM, Nowak S, Vaidyanathan S, Kaufman N, Chittum A. The 2010 state energy efficiency scorecard. Waschington, D.C.: American Council for an Energy-Efficient Economy; 2010.

[8] Sciortino M, Neubauer M, Vaidyanathan S, Chittum A, Hayes S, Nowak S, et al. The 2011 State Energy Efficiency Scorecard. Washington, D.C.: American Council for an Energy-Efficient Economy; 2011.

[9] Boyle S. DSM progress and lessons in the global context. Energy Policy 1996;24:345-59.

[10] UNFCCC. About CDM. not dated. 〈http://cdm.unfccc.int/about/index.html $\rangle$. [accessed 2908 2012].

[11] World Bank. Independent evaluation group. Climate change and the World Bank group-Phase I: An evaluation of World Bank win-win enegry policy reforms. Washingtopn, D.C.The World Bank; 2009.

[12] Haney AB, Jamasb T, Platchkov LM, Pollitt MG. Demand-side management strategies and the residential sector: lessons from international experience. Cambridge: Electricity Policy Research Group. University of Cambridge; 2010.

[13] IEA. Energy Efficiency Governance Handbook. Paris: OECD/IEA; 2010.

[14] Birner S, Martinot E. Promoting energy-efficient products: GEF experience and lessons for market transformation in developing countries. Energy Policy 2005;33:1765-79.

[15] IEA. Energy efficiency updades. Paris: OECD/IEA; 2003.

[16] EUSUSTEL. The European Union, 25 different countries, 25 different energy policies...? An overview. Leuven: Leander Cosijns and William D'haeseleer, editors.; 2006.
[17] IEADSM. State of DSM and EE in the World. Paris: International Energy Agency Demand-side Management Programme; 2005.

[18] AEA. Energy efficiency policies and measures in Austria. Vienna: Austrian Energy Agency; 2009.

[19] IEA. Energy policies of IEA Countries: Austria 2007 review. Paris: IEA; 2008

[20] IEA. Energy policies of IEA Countries: Belgium 2009 review. Paris: OECD/IEA 2010.

[21] Ademe. Energy efficiency indicators in Europe-Cyprus. May 2011. 〈http:// www.odyssee-indicators.org/publications/country_profiles_PDF/cyp.pdf $\rangle$. [accessed 01052012 ].

[22] IEA. Implementing energy efficiency policies: are IEA member countries on the track?. Paris: OECD/IEA; 2009

[23] IEA. Energy policies of IEA countries: Ireland 2007 review. Paris:OECD/IEA; 2007

[24] ISIS, IRL 19 Demand side management measures. 2012. 〈http://www.muredata base.org/public/mure pdf/tertiary/IRL19.PDF $\rangle$ [accessed 1808 2012].

[25] ISIS. "Powerful Savings for industry" Brochure IRL 4. 2008. 〈http://www.mureda tabase.org/public/mure_pdf/industry/IRL4.PDF $>$. [accessed 1808 2012].

[26] Geller H, Harrington P, Rosenfeld AH, Tanishima S, Unander F. Policies for increasing energy efficiency: thirty years of experience in OECD countries. Energy Policy 2006;34:556-73.

[27] ISIS. GER34 Energy efficiency campaign. 2011. 〈http://www.muredatabase org/public/mure_pdf/industry/GER34.PDF $\rangle$. [accessed 0406 2012].

[28] Wasserman N, Neme C. Achieving energy efficiency-a global best practices guide on government policies. Sleeping Lion Consulting 2012.

[29] ISIS. NLD2-The Environmental Action Plan of the energy distributiom companies," 2007. 〈http://www.muredatabase.org/public/mure_pdf/ter tiary/NLD2.PDF $>$. [accessed 1808 2012].

[30] ISIS. MURE II-The Netherlands. 2012. 〈http://www.muredatabase.org/pub lic/mure_pdf/tertiary/NLD8.PDF $\rangle$. [accessed 1808 2012].

[31] IEA. Energy policies of IEA Countries: The Netherlands 2008 review. Paris: OECD/IEA; 2009.

[32] ISIS. SLO 15: Financial incentives for efficient electricity consumption in the public sector. 2012. <http://www.muredatabase.org/public/mure_pdf/ter tiary/SLO15.PDF $\rangle$. [accessed 1808 2012].

[33] IEA. Energy policy of IEA Countries: Switzerland-2012 review. Paris: OECD/ IEA; 2012

[34] Singh J, Limaye DR, Henderson B, Shi X. Public procurement of energy efficiency services-lessons from international experience. Washington, D.C.: The International Bank for Reconstruction and Development/ The World Bank; 2010.

[35] RAP. State EE Policy Inventory for Western States through 2010. 2011. 〈http:/ www.raponline.org/document/download/id/4741 >. [accessed 2607 2012].

[36] ACEEE. State Energy Efficiency Policy Database. 2012. 〈http://www.aceee. org/energy-efficiency-sector/state-policy/> [accessed 29012013 ].

[37] RAP. State EE Policy Inventory for Southeastern States Through 2010. 2011. 〈http://www.raponline.org/document/download/id/4741〉. [accessed 2607 2012].

[38] RAP. State EE Policy Inventory for Midwestern States Through 2010. $2011<\mathrm{http}$ // www.raponline.org/document/download/id/4745 >. [accessed 2607 2012].

[39] Jannuzzi GDM. Power sector reforms in Brazil and its impacts on energy efficiency and research and development activities. Energy Policy 2005; 33:1753-1762.

[40] Hu Z, Moskovitz D, Zhao J. Demand-side management in China's restructured power industry. Washington, D.C: The World Bank; 2005

[41] GEF, GEF. Project details - Argentina - Energy Efficiency Project. 2008 <http://www.gefonline.org/ProjectDocs/Climate\%20Change/Argentina\%20-\% 20Energy\%20Efficiency\%20Project/AR\%20GEF\%20EE\%20PD\%20on\%20April\% 2011\%202008.master\%20copy\%20clean.doc >. [accessed 0706 2012].

[42] Ashar S, Knight D. Medium-sized project grant from the global environment facility (GEF) to the International Institute for Energy Conservation (IIEC) for the IFC/GEF Argentina Efficient Streetlighting Program. IIEC; 2002.

[43] Morey, J. Clean power in Costa Rica: opportunities and barriers-strategies for a fossil fuel-free power sector by 2025. 2006.

[44] United Nations Economic Commission for Europe. Financing global climate change mitigation. Geneve: United Nations; 2010.

[45] World Bank Environment Department-climate change team. World Bank GEF energy efficiency portfolio review and practitioners' handBook. 2004.

[46] GEF. GEF_project details: Global-efficient lighting initiative (Tranche I). 2009. 〈http://www.gefonline.org/ProjectDocs/M\&E/PIR/2009\%20PIR/WB/IFC/Comple tion\%20Reports/Proj\%20No.\%20502238\%20PCR.doc $\rangle$. [accessed 0906 2012].

[47] Waide P, Buchner B. Utility energy efficiency schemes: savings oblligations and trading. Energy Efficiency 2008;1:297-311.

[48] International Institute for Energy Conservation. Demand side management best practices guidebook for Pacific Islands Power Utilities. SOPAC/UNDESA, 2006.

[49] Sarkar A, Singh J. Financing energy efficiency in developing countries-lessons learned and remaining challenges. Energy Policy 2010;38:5560-71.

[50] Vashishtha S, Ramachandran M. Multicriteria evaluation of demand side management (DSM) implementation strategies in the Indian power sector. Energy 2006;31:2210-25.

[51] Singh, J. World Bank GEF energy efficiency portfolio review and practitioners' handbook. World Bank Environment Department_Climate Change Team; 2004.

[52] Al-Badi AH, Malik A, Gastli A. Sustainable energy usage in Oman-opportunities and barriers. Renewable and Sustainable Energy Reviews 2011;15:3780-8.

[53] IEA. Energy policies of IEA Countries: New Zealand 2011 Review. Paris: OECD/IEA; 2011. 
[54] Nair NKC, Nayagam R, Francis R. New Zealand utility experiences with demand side management. In power and energy society general meeting-conversion and delivery of electrical energy in the 21st century, 2008 IEEE. 2008.

[55] UNDESA, SOPAC. SOPAC Compendium - digital collection of the entire body of knowledge of SOPAC from 1972 (than CCOP/SOPAC) to 2010. 2004. <http:// ict.sopac.org/compendium/project/show/2425782 >. [accessed 2901 2013].

[56] Global Sustainable Electricity Partnership. Capacity Building. 2010. <http:/ www.globalelectricity.org/en/index.jsp? $\mathrm{p}=118 \& \mathrm{f}=277\rangle$. [accessed 2901 2013].

[57] DR. Despacho n. $15546 / 2008$. Diário da República, $2^{\underline{a}}$ série No. 107, de 4 de Julho de 2008, p. 24886-24895.

[58] ERSE. Plano de Promoção da Eficiência no Consumo de Energia Eléctrica para 2011-2012. Lisboa: Entidade Reguladora dos Serviços Energéticos; 2010.

[59] DR. Despacho n ${ }^{\circ} 18$ 412-A/2001. Diário da República, $2^{\underline{a}}$ série, No. 203, de 1 de Setembro de 2001, pp. 14944(1)-(91), 2001.

[60] ERSE. Plano de Gestão da Procura 2002-2005. ERSE, 2009. 〈http://www.erse. $\mathrm{pt} / \mathrm{pt} / \mathrm{planodepromocaodaeficiencianoconsumoppec/edicoesPPEC/pgp2002a}$ 2005/Paginas/default.aspx $>$. [accessed 0406 2012].
[61] ERSE. Análise da execução do plano de gestão da procura no período de regulação 2002 a 2004 e 2005. Lisboa: ERSE; Not dated.

[62] ERSE. Plano de Promoção da Eficiência no Consumo de Energia Eléctrica para 2008. Lisboa: Entidade Reguladora dos Serviços Energéticos; 2007.

[63] ERSE. Plano de Promoção de Eficiência no Consumo de Energia Eléctrica para 2007. Lisboa: Entidade Reguladora dos Serviços Energéticos; 2007.

[64] ERSE. Plano de Promoção da Eficiência no Consumo de Energia Eléctrica para 2009-2010. Lisboa: Entidade Reguladora dos Serviços Energéticos; 2009.

[65] ERSE. Agentes do Sector. 2012. 〈http://www.erse.pt/pt/electricidade/agentes dosector/Paginas/default.aspx $\rangle$. [accessed 0908 2012].

[66] Apolinário, I, Barros, CC, Santo, CE, Ferreira, A, Ferreira, L, Madeira, B et al. Results from a competitive tender mechanism to promote energy efficiency in Portugal. In: 9th International Conference on the European Energy Market, May, 10-12, 2012, Florence; 2012. 